\title{
Demographic vulnerability of the clonal and endangered meadow thistle
}

\author{
Eelke Jongejans • Natasha de Vere • \\ Hans de Kroon
}

Received: 5 September 2007 / Accepted: 13 January 2008/Published online: 10 February 2008

(C) The Author(s) 2008

\begin{abstract}
For effective management of endangered species it is pivotal to understand why a species is endangered and which key life cycle components are involved in its response to environmental changes. Our objective was to investigate the response of rosettes of the redlisted clonal herb Cirsium dissectum to anthropogenic nutrient enrichment, which threatens its populations, and the consequences of these responses for its population dynamics. We constructed matrix population models with demographic data from three
\end{abstract}

\section{E. Jongejans $(\bowtie)$}

Nature Conservation and Plant Ecology Group,

Wageningen University, Droevendaalsesteeg 3a, 6708 PB

Wageningen, The Netherlands

e-mail: E.Jongejans@science.ru.nl

\section{E. Jongejans $\cdot$ H. de Kroon}

Department of Experimental Plant Ecology, Radboud University Nijmegen, Toernooiveld, 6525 ED Nijmegen, The Netherlands

E. Jongejans

Department of Biology, The Pennsylvania State

University, 208 Mueller Laboratory, University Park, PA 16802-5301, USA

N. de Vere

Terrestrial Ecology Research Group, School of Biological Sciences, University of Plymouth, Plymouth PL4 8AA, UK

\section{N. de Vere}

Whitley Wildlife Conservation Trust, Totnes Road, Paignton, Devon TQ4 7EU, UK populations and four annual transitions and we decomposed the spatiotemporal variation in projected population growth rates into contributions from life cycle components. These patterns were compared with below-ground rosette dynamics in different fields, and with the below- and above-ground rosette dynamics in a garden experiment with nutrient enrichment and competing grasses. The decomposition analysis revealed that increased clonal rosette formation and decreased rosette survival were driving the spatial variation in the population growth rate. Excavating the below-ground rhizome network revealed a higher rosette turn-over in experimentally fertilized garden plots, which not only resulted in increased plot-level extinction, but also in increased spread of the clonal offspring. This supported the observed trend among field populations: rosette formation trades off with rosette survival. Surviving seedlings were only found in areas where the topsoil had been removed. The endangered $C$. dissectum is vulnerable when its habitat becomes more productive, because this species does not have the necessary capability to build up biomass. Small-scale disturbances such as created by sodcutting or trampling cattle are essential for seedling establishment and necessary to render the explorative strategy of rhizomatous clonal spread successful.

Keywords Clonal propagation - Life table response experiments (LTRE) · Matrix population model . Nutrient enrichment · Rosette turn-over · Topsoil removal 


\section{Introduction}

Population viability analyses investigate which key life cycle components are limiting population growth of particular endangered species (Menges 1990, 2000; Boyce 1992). Few population viability analyses, however, include experiments to study the mechanisms that underlie the vulnerability of those life cycle components (Colling and Matthies 2006). Understanding how environmental changes that threaten the persistence of populations affect individual plant performance and the resulting population dynamics can help to augment conservation management (Gotelli and Ellison 2002; Ehrlén et al. 2005; Maschinski et al. 2006). Here we aim to shed light on the causes of the rarity of a Red List clonal plant species by studying its response to increasing grassland productivity, both in a series of natural populations and in a garden experiment.

Clonal growth by long stolons or rhizomes can be a successful life history strategy as runner production forms an effective way to exploit heterogeneous resources and to rapidly occupy space (Eriksson 1986; de Kroon and Schieving 1990; Lenssen et al. 2005). However, runners are not a guarantee for high abundance in a landscape, since the percentage of rare species among plants with rhizomes longer than $10 \mathrm{~cm}$ is equal to that percentage for other types of clonal growth (Klimeš and Klimešová 2000). The rhizomatous meadow thistle, Cirsium dissectum (L.) Hill., is an inhabitant of nutrient-poor, species-rich, wet grasslands and has an Atlantic distribution in Northwest Europe. Habitat destruction, fragmentation, drainage, acidification, and nutrient enrichment (Saunders et al. 1991; Roem and Berendse 2000; Gotelli and Ellison 2002) have led to reductions in the number and size of habitat patches suitable for C. dissectum (Buck-Sorlin and Weeda 2000; Soons et al. 2005). This early-successional grassland species is replaced by taller plants with more aboveground biomass when nutrient enrichment speeds up the process of grassland succession. It is unclear, however, which key life cycle components are involved in the vulnerability of $C$. dissectum populations to these habitat changes.

Clonal plants such as $C$. dissectum have been hypothesized to respond to increased vegetation biomass by increasing either sexual reproduction or clonal propagation (Abrahamson 1980; Loehle 1987).
This response depends on the life history of a species and on the expected relative gain of increasing either way of reproduction. For C. dissectum Jongejans et al. (2006a) not only found that fertilizing plots with rosettes amid competitors increased the plotlevel extinction risks, but also that in fertilized plots with survivors a larger proportion of rosettes flower compared to plants in unfertilized plots, while the number of living rosettes and total biomass was not significantly affected. This increased sexual reproductive allocation was interpreted as a strategy of escape in space as seeds may disperse to more favorable sites. It is still unknown, however, what happens belowground: is clonal propagation affected as well? Rhizome formation can potentially be an effective way to explore the vegetation to reach patches with less competitive pressure. And can the overall response of this species to nutrient enrichment form an explanation for its rarity?

To be able to translate experimental findings to implications for natural populations, it is important to know whether differences in both sexual and clonal reproduction over a productivity gradient are also found in the field, and whether the dynamics of natural populations are sensitive to these responses. Any change in one or more components of the life cycle needs to be evaluated in the context of the entire life cycle (Ehrlén 2003), since changes in components for which the population growth rate is very sensitive will affect the population dynamics more than changes in components with small sensitivity values (Caswell and Werner 1978; Griffith and Forseth 2005).

In this article we study the role of clonal growth and seed production in the population dynamics of C. dissectum in its response to nutrient enrichment and increased grassland productivity. We combine field observations, population models, and experiments. First we use matrix projection models to study the population dynamics of $C$. dissectum in 3 sites of contrasting productivity for 4 years and we use decomposition analyses to quantify how variation in rosette survival, sexual reproduction, and clonal propagation contributed to the variation in the projected population growth rate.

Second we investigate which aspects of clonal spread are involved in the response of $C$. dissectum to increased grassland productivity, and to the resulting competition for light, by collecting new data on the dynamics of rhizomes from a garden experiment 
described in Jongejans et al. (2006a). Last we compare plant sizes, sexual reproduction, and clonal propagation between 5 meadow populations to see if the same trends in above- and below-ground biomass investment are found over a natural gradient of site productivity. Two populations in topsoil removed areas are also studied to evaluate if topsoil removal is a successful management option to counter nutrient enrichment and to rejuvenate $C$. dissectum populations. This combination of experiments, field observations and population models was designed to reveal which life cycle components are responsible for the vulnerability of this endangered species to the effects of nutrient enrichment by answering the following questions: Which life cycle components (e.g., survival, clonal propagation or seed production) contribute most to population growth and which of those components vary between site and years? How exactly does $C$. dissectum respond to nutrient enrichment above- and belowground? And how can these insights be used to augment conservation management?

\section{Material and methods}

Study system

Meadow thistle, C. dissectum (L.) Hill Asteraceae, is a rhizomatous herb that forms rosettes with up to 5 softly prickled leaves (de Vere 2007). In winter the above-ground rosette is reduced to one or two small, fleshy leaves. Flowering stems are formed apically. During stem elongation rosette leaves are raised up to half way up the 60-cm-tall flowering stem on which in most cases only a single flower head is formed. After seed set the rosette dies off. Cirsium dissectum is mostly restricted to oligotrophic wet grasslands and heathlands over its entire Atlantic distribution from southwest France to northwest Germany and on the British Isles (Blackstock et al. 1998; de Vere 2007). These habitats have declined substantially in number and extent (Kay and John 1994; Buck-Sorlin and Weeda 2000). For instance, $57 \%$ of the $C$. dissectum populations in Germany are estimated to have become extinct since 1930, and many surviving populations were reduced greatly in size, due to drainage and fertilization of the sites they inhabit (Buck-Sorlin 1993). Meadow thistles are also sensitive to the effects of acidification (de Graaf et al. 1997, 1998; Lucassen et al. 2003). Soons et al. (2005) have shown for this species that its habitat connectivity has decreased sharply during the 20th century due to habitat fragmentation. C. dissectum is redlisted in The Netherlands, Germany, and Belgium. The nomenclature in this article follows van der Meijden (1996).

In the various parts of the present study on C. dissectum we used up to 5 meadows (M) and 2 topsoil removed areas (TSR) in The Netherlands. In order of increasing productivity (i.e., mown biomass, Table 1) the studied meadows were Nijkampse heide (M1; 52 $\left.{ }^{\circ} 02^{\prime} \mathrm{N}, 6^{\circ} 33^{\prime} \mathrm{E}\right)$, Stelkampsveld (M2; $52^{\circ} 07^{\prime} \mathrm{N}$, $\left.6^{\circ} 29^{\prime} \mathrm{E}\right)$, Bennekomse Meent (M3; 52 $\left.00^{\prime} \mathrm{N}, 5^{\circ} 36^{\prime} \mathrm{E}\right)$, Konijnendijk (M4; $\left.52^{\circ} 02^{\prime} \mathrm{N}, 6^{\circ} 26^{\prime} \mathrm{E}\right)$, and Veerslootlanden $\left(\mathrm{M} 5 ; 52^{\circ} 36^{\prime} \mathrm{N}, 6^{\circ} 08^{\prime} \mathrm{E}\right)$. All sites were mown once per year after which hay is removed. Site M5 was mown twice in some years to halt encroachment of common reed, Phragmites australis (Cav.) Steudel. The topsoil of small areas adjacent to the meadows M1 and M4 had been removed (i.e., sod-cutting) by the owner, Dutch State Forestry, to reduce soil fertility in 1997. These sod-cut areas are referred to as TSR1 and TSR4 throughout this article.

Natural population dynamics in three sites of contrasting productivity

To study the natural population dynamics of $C$. dissectum we established permanent plots in which all rosettes were followed from 1999 to 2003 . The $1 \times 1 \mathrm{~m}$ permanent plots were established in April 1999 at three sites: five plots in M3, six in M4, and two in M5. Each year in June, when C. dissectum flowers, all rosettes in the permanent plots were mapped to $5 \mathrm{~mm}$ accuracy, which proved to be adequate for identifying surviving rosettes. We counted the number of rosette leaves and determined maximum leaf length at each census. A combination of plant size, flowering status, and the formation of side-rosettes was used to classify rosettes. We distinguished six classes (Fig. 1; Appendix 1):

1. Seedlings $(s d l)$ are tiny rosettes with no leaves longer than $2 \mathrm{~cm}$.

2. Small vegetative rosettes $(s m l)$ : larger than seedlings but with no leaves longer than $12.5 \mathrm{~cm}$.

3. Large vegetative rosettes $(l r g)$ have longer leaves than small rosettes. 


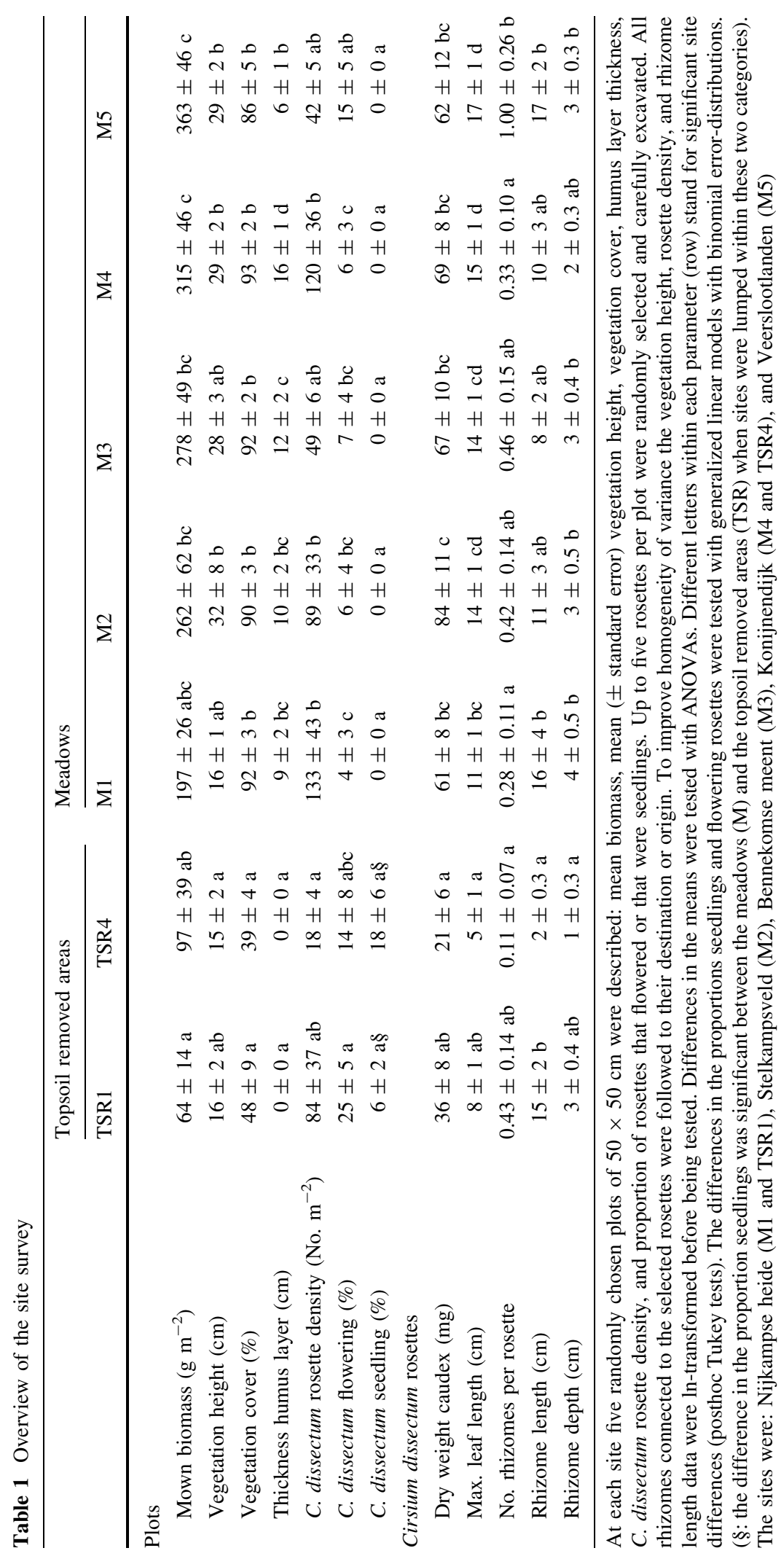


4. Flowering rosettes (flow) are grouped irrespective of rosette size.

5. Vegetative clonal offspring (cl.v) are new rosettes formed by rhizomes since the census of the previous year and do not flower. Surviving cl.v become sml, lrg, or flow the next year (Fig. 1).

6. Flowering clonal offspring (cl.f) are new flowering rosettes formed by rhizomes since the census of the previous year.

The demographic data from the permanent plots were used to parameterize $6 \times 6$ projection matrices of the form $\boldsymbol{A}_{i j}$ in which each element, $a_{i j}$, represents the transition from the $j$ th category in year $t$ to the $i$ th category in year $t+1$. The 36 matrix elements were classified as different life history components: fecundity $(F)$; growth $(G)$; clonal propagation $(C)$; survival of clonal offspring $(T)$; stasis $(S)$; and retrogression $(R)$ (for a similar classification see Jongejans and de Kroon 2005). Growth is defined as the transition of a smaller or vegetative stage class to a larger or flowering stage class by a surviving rosette. Stasis means that a rosette remains in the same class. Rosettes that retrogress survive but decrease in size. Fecundity of the flowering plants was calculated as the product of the establishment probabilities per seed, the average seed production of the average flowering rosette in each population, and the mean number of observed flower heads per flowering rosette in a population in year $t$. Seedling establishment rates were determined in a previous study in which seeds were added to small plots in sites M3 and M4 in 2 years: per seed on average $2.5 \times 10^{-4}$ seedlings and $5.0 \times 10^{-4}$ seedlings that grow into small rosettes within a year were recorded (Jongejans et al. 2006b). No seed bank was included in the population model because $C$. dissectum seeds are not long-lived (Thompson et al. 1997).

Three assumptions were made during the construction of the population matrices. First, since too few seedlings were present in both the permanent plots and the seed addition experiment to quantify seedling fate reliably, we estimated seedling stasis and growth conservatively high (30\% and $15 \%$, respectively) at
Fig. 1 Life cycle of Cirsium dissectum. The arrows are year-to-year transitions and represent the used population matrix model. The values of the overall mean matrix are given with the arrows. Closed lines indicate the survival of a rosette, dashed lines sexual reproduction, and dotted lines exclusively clonal propagation. The six stages are: seedlings ( $s d l)$, small $(\mathrm{sml})$ and large (lrg) vegetative rosettes, flowering rosettes (flow), and new clonal offspring that either flower (cl.f) or not (cl.v). All flowering rosettes die. 'Rhiz.' points at the rhizomes that have formed the clonal offspring. If non-flowering clonal offspring (cl.v) survive till the next year these rosettes become either sml, lrg, or flow

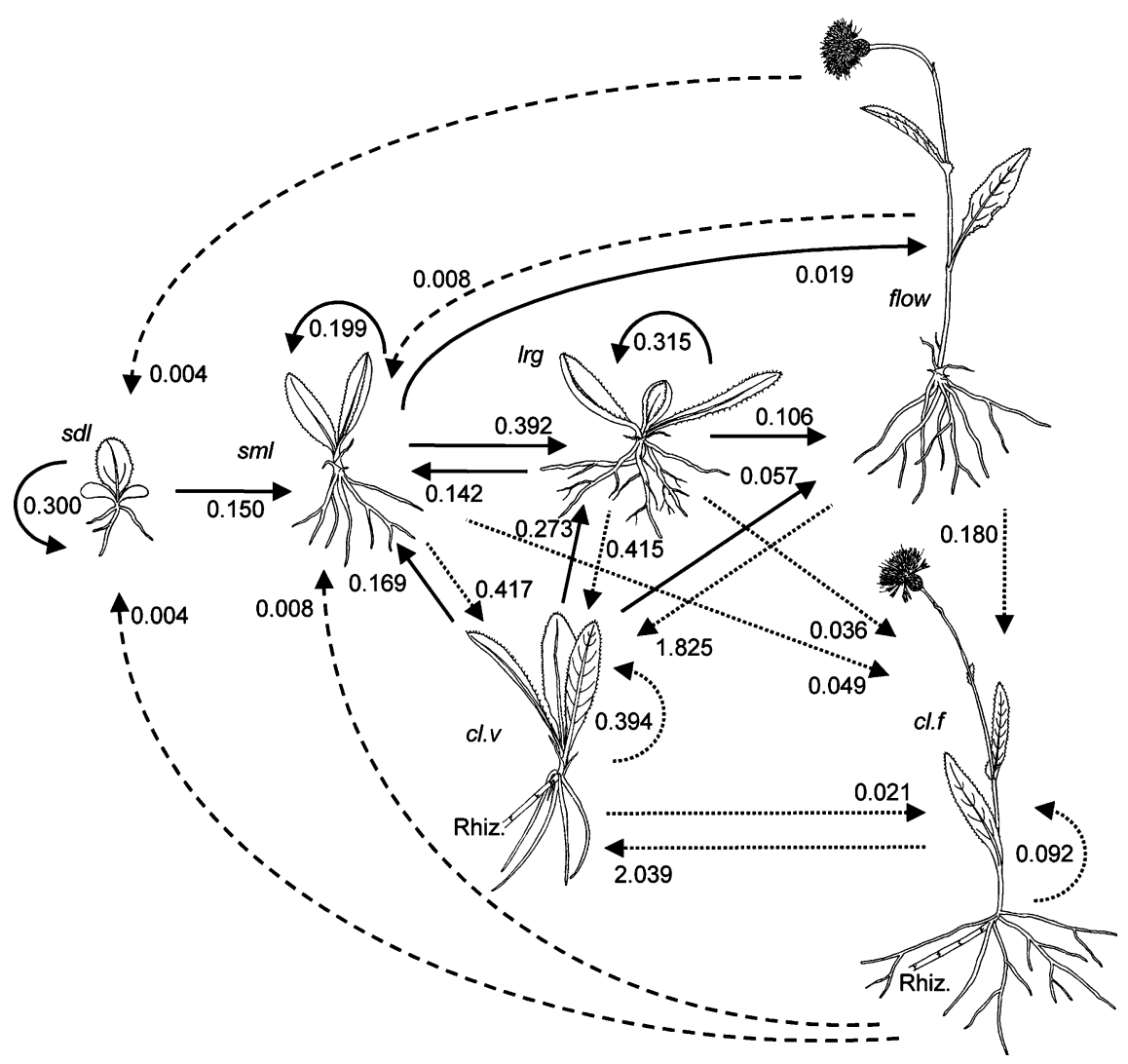


levels that were found for another Asteraceae species, Hypochaeris radicata L. (Jongejans and de Kroon 2005). Second, because rhizomes are invisible without excavations we could not determine which new rosette in year $t+1$ was clonally produced by which old rosette in year $t$. Therefore we assigned new clonal offspring to old rosettes of the stage classes sml, $\mathrm{lrg}$, flow, cl.v or cl.f, according to a probability function that was based on two factors: the proportion of all rosettes in year $t$ belonging to a certain class, and the average number of rhizomes produced by either a vegetative ( $\mathrm{sml}, \mathrm{lrg}$, and $\mathrm{cl.v}$ ) or a flowering (flow and $c l . f)$ rosette. The latter was calculated separately for each population and was based on excavated plants (see site survey section below). No distinction was made between the rhizome production of different vegetative size classes, as there was no significant relationship between the number of produced rhizomes and plant size classified as either sml or lrg. Berg (2002) made similar assumptions in his Oxalis acetosella $\mathrm{L}$. model. Third, some transition probabilities had to be estimated when sufficient data were absent: in the first annual transition (1999-2000) it was not possible to observe the fates of $c l . v$ and $c l . f$ because we did not know which rosettes were produced clonally in the previous year. These uncertain transition probabilities were estimated from all observations over the years for that class in the same population. Apart from the cl.v and cl.f classes in the first annual transition, observation numbers were too small (i.e., when a stage class contained less than seven rosettes) in only $13 \%$ of the cases.

For each of the 12 (3 sites with 4 annual transitions each) constructed projection matrices we calculated the life expectancy of vegetative clonal offspring (cl.v) (using Eq. 3 in Cochran and Ellner 1992). The dominant eigenvalue and the accompanying right eigenvector of each matrix were used as the projected population growth rate, $\lambda$, and the stable-state distribution, respectively (Caswell 2001). To construct $95 \%$ confidence intervals for $\lambda$, we applied the bootstrapping method by re-sampling the count dataset of observed rosette fates of each matrix 3,000 times (Efron 1982; Kalisz and McPeek 1992; Caswell 2001) in which the survival $(T, G, S$, and $R$ ) and rhizome formation $(C)$ observations were resampled for all classes separately. New sexual reproduction $(F)$ elements were calculated after resampling the dataset of number of flower heads of the observed flowering rosettes. The upper and lower limits of the $95 \%$ confidence intervals were adjusted for small deviations between the mean $\lambda$ of the 3,000 newly constructed matrices and the $\lambda$ of the original matrix (Caswell 2001).

To decompose variation in $\lambda$ we applied factorial life table response experiments (LTRE): a decomposition analysis with two factors (Horvitz et al. 1997; Caswell 2001):

$\lambda^{(m n)} \cong \lambda^{(\cdot)}+\alpha^{(m)}+\beta^{(n)}+(\alpha \beta)^{(m n)}$

in which a given $\lambda$ of the $m$ th site and $n$th year is written as the sum of $\lambda^{(\cdot)}$ (the $\lambda$ of the mean of all matrices), the main effect of the $m$ th site, $\alpha^{(m)}$, the main effect of the $n$th annual transition, $\beta^{(n)}$, and the residual 'interaction' effect, $(\alpha \beta)^{(m n)}$. The main effects can be estimated by filling in this equation first for each level of the main effects separately, while ignoring the interaction term. The main and interaction effects can now be decomposed into contributions from each matrix element (Caswell 2001):

$$
\begin{gathered}
\tilde{\alpha}^{(m)}=\left.\sum_{i, j}\left(a_{i j}^{(m \cdot)}-a_{i j}^{(\cdot \cdot)}\right) \frac{\partial \lambda}{\partial a_{i j}}\right|_{\frac{1}{2}\left(A^{(m \cdot)}+A^{(\cdot)}\right)} \\
\tilde{\beta}^{(n)}=\left.\sum_{i, j}\left(a_{i j}^{(\cdot n)}-a_{i j}^{(\cdot \cdot)}\right) \frac{\partial \lambda}{\partial a_{i j}}\right|_{\frac{1}{2}\left(A^{(\cdot n)}+A^{(\cdot)}\right)} \\
(\tilde{\alpha \beta})^{(m n)}=\left.\sum_{i, j}\left(a_{i j}^{(m n)}-a_{i j}^{(\cdot)}\right) \frac{\partial \lambda}{\partial a_{i j}}\right|_{\frac{1}{2}\left(A^{(m n)}+A^{(\cdot)}\right)} \\
-\tilde{\alpha}^{(m)}-\tilde{\beta}^{(n)}
\end{gathered}
$$

In these equations the differences between each matrix element value and the overall mean value of that matrix element are multiplied by the sensitivity values of the matrix halfway between the matrix of interest and the overall mean matrix, $A^{(\cdot)}$. The resulting contribution matrices of the main and interaction effects contain both positive and negative values, which we summed separately for each of the 6 life history components $(F, G, C, T, S$, and $R$ ) (see also Jongejans and de Kroon 2005).

We studied the consequences of the observed population dynamics for the extinction risks of the 3 populations in computer simulations. The simulations started with either 100 or 10,000 ramets that were distributed over the 6 stage classes proportional to the stable stage distribution of the mean matrix of 
the studied population. Environmental stochasticity was introduced by multiplying the population size vector by a randomly chosen transition matrix (out of the 4 matrices constructed for each population) each annual time step. Demographic stochasticity was not included. A population was deemed extinct when the sum of the population size vector was less than 1 . Each simulation scenario was repeated 100,000 times.

Garden experiment: effect of nutrient enrichment on clonal spread and rosette turn-over

To investigate the effects of nutrient enrichment on clonal spread and rosette turn-over we gathered new data from a 3-year garden experiment described in Jongejans et al. (2006a): we now present previously unpublished data on the spatial location of the clonal offspring in the experiment and on below-ground, rhizomatous connections between live and dead rosettes. The experiment in the nutrient-poor, sandy garden of Wageningen University consisted of circular $($ diameter $=50 \mathrm{~cm})$ plots in the middle of which one $C$. dissectum rosette was planted. In each plot 6 clumps of 4 shoots of the tall grass Molinia caerulea (L.) Moench were placed around the $C$. dissectum rosette in a $10-\mathrm{cm}$-sided hexagon. This set-up mimicked grasslands containing both $C$. dissectum and plants that rapidly increase their biomass when more nutrients are available. During the second and third year of the experiment half of the 80 plots were enriched with the equivalent of $120 \mathrm{~kg} \mathrm{~N} \mathrm{ha}^{-1}$ year $^{-1}$ by applying an Hoagland's stock solution (containing $\mathrm{KNO}_{3}, \mathrm{Ca}\left(\mathrm{NO}_{3}\right)_{2}, \mathrm{MgSO}_{4}$, and $\left.\mathrm{NH}_{4} \mathrm{H}_{2} \mathrm{PO}_{4}\right)$, while the other half of the plots received no fertilization. The original experiment also comprised a flower bud removal treatment (to quantify the costs of sexual reproduction on vegetative growth) that was crossed with the nutrient enrichment in a $2 \times 2$ experimental design. This bud removal treatment was therefore included in the full statistical analyses in Appendix 2. In the results section, however, we focus on what is relevant for this study: the main effects of nutrient enrichment on clonal spread and rosette turn-over (i.e. the birth and death rates of clonal offspring).

We mapped the position of all $C$. dissectum rosettes in the circular plots just before the final harvest at the end of the third growing season. To study the degree of spatial spread from the initial rosette position, the distance of each rosette to the geometric center of the $6 \mathrm{M}$. caerulea clumps was determined on the maps. Detailed observations were made on the below-ground rhizome network in 12 randomly selected plots ( 3 in each combination of the nutrient addition and bud removal treatments). Highpressure air was used to remove the soil around the rosettes to reveal and map the rhizomes and decaying rosettes without leaves. Rhizome length was measured as the shortest distance on the map between the connected rosettes.

Site survey: above- and below-ground plant performance in topsoil removed areas and in meadows along a productivity gradient

Next we determined if the same trends in above- and below-ground biomass investment also occur in natural populations over a larger productivity gradient and if topsoil removal is an effective management option to increase $C$. dissectum plant performance. Therefore we recorded the following parameters in both topsoil removed areas and in all 5 meadows: the size, flowering status and density of rosettes, seedling establishment, rhizome formation and other site characteristics. Between July 26th and August 3rd, 2001, five 50 by $50 \mathrm{~cm}$ square plots were randomly laid out in each of the 7 sites. Plots containing less than a minimum number of rosettes were omitted and replaced by new random plots. The meadow plots had to contain at least 5 rosettes; this was reduced to a minimum of 2 rosettes for the sod-cut areas where C. dissectum density was lower.

Within each of the 35 plots we estimated the height of the vegetation (without flowering stems) and the percentage vegetation cover. The positions of all $C$. dissectum rosettes were mapped with an accuracy of $5 \mathrm{~mm}$. The size of each rosette was determined by the number of leaves and their maximum length. For flowering individuals the height of the stem was measured. Up to 5 rosettes per plot were randomly selected and carefully excavated. Rhizomes connected to these selected rosettes were followed to their destination or origin, which in some cases was outside the plots. We measured the maximum depth of the excavated rhizomes and calculated the length of a rhizome based on the shortest distances between the rosettes 
that it connected. The vegetation in the plot was clipped at a height of $4 \mathrm{~cm}$ above the soil surface, and weighed after being dried for $48 \mathrm{~h}$ at $70^{\circ} \mathrm{C}$. To investigate whether soil structure affected rhizome growth we determined the average thickness of the humus layer from 3 soil cores taken next to each plot.

\section{Results}

Natural population dynamics

The data on survival, rosette growth, and clonal propagation from the permanent plots in the meadows M3, M4, and M5 resulted on average in projection matrices with population growth rates around unity $(\lambda$ ranging from 0.68 to 1.30 , Fig. 2). Although the ranges of $\lambda$ of the 3 sites overlapped, there were distinct differences between the populations: vegetative rosettes in site M4 were smaller than rosettes in the other two sites (the ratio sml:lrg in the stable stage distribution of the mean site matrix was 1:0.36 in M4, 1:7.5 in M3, and 1:5.6 in M5). M5, the most productive site, had both the highest rate of clonal propagation: the number of clonal offspring per rosette (see Fig. 1) averaged 0.649 in M5 versus a

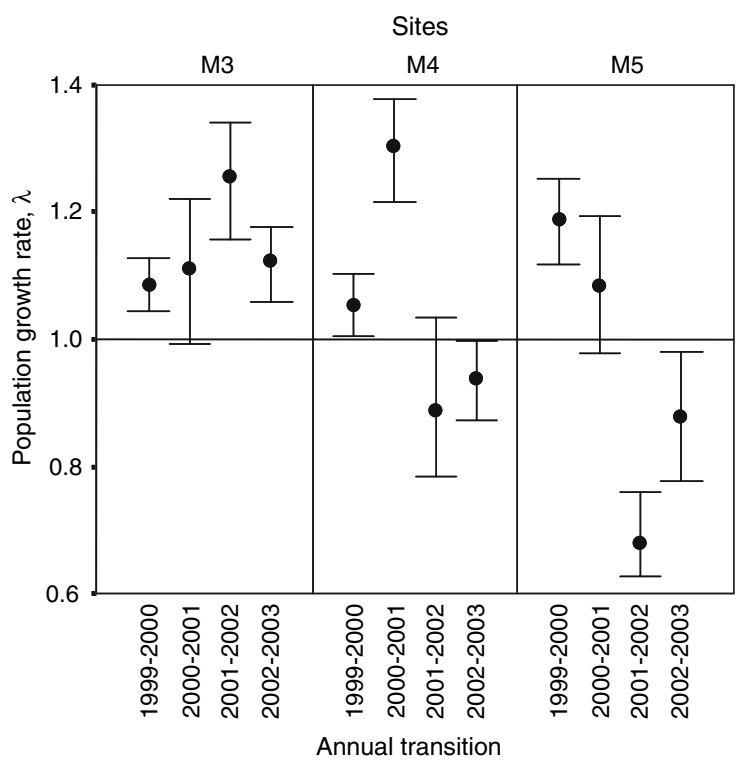

Fig. 2 Projected population growth rate, $\lambda$, and bootstrapped 95\% confidence intervals for all 12 Cirsium dissectum matrices (see Appendix 1) mean of 0.496 in M3 and M4. However, sites M3 and M4 had 53\% higher vegetative rosette survival rates than M5: 0.631 on average for stages sml, lrg, and cl.v in M3 and M4 versus 0.412 in M5. The life expectancy of vegetative clonal offspring (cl.v), averaged over the 4 annual transitions, was 2.8 years in M3, 2.6 years in M4, and 1.3 years in M5. Only 3 seedlings in total were found during the 5 summers in which the permanent plots were censused and no seedling survival was observed.

Due to such low sexual reproduction, seedlings made up less than $0.1 \%$ of the projected stable stage distribution (i.e., the relative number of individuals in each stage class) in all 3 populations, even though seedling survival was modeled conservatively high. The temporal correlation between $\lambda$ and the stable stage distribution differed between sites: in the most productive site, M5, $\lambda$ was positively correlated with the projected flowering percentage of all rosettes. Please note that this correlation is not mediated through sexual reproduction, which contributes little to $\lambda$. Instead, in good years, plant growth was larger, causing increases in both $\lambda$ and the proportion flowering. In contrast, the proportion of all rosettes that consisted of newly produced clonal offspring was constantly high at about $76 \%$ in M5 over the years (Fig. 3). The opposite pattern was found in site M4 where there was only a weak correlation of $\lambda$ with the proportion of rosettes that flower, but the percentage clonal offspring was twice as high in good years (53\%), compared to poor years (28\%). Population M3 was intermediate to the other two.

To analyze what differences in matrix elements could explain the variation in $\lambda$ between sites and years we decomposed the variation in $\lambda$ according to the LTRE technique. The model fitted the data well as the difference between the observed and modeled population growth rates was on average $0.13 \%$. The two-way LTRE revealed larger year (mean $|\beta|=11.2)$ than site (mean $|\alpha|=6.51)$ effects. Interaction (mean $|\alpha \beta|=10.2$ ) effects were almost as large as the year effects. The lower mean $\lambda$ in site M5 was mostly due to low survival of 1 -year-old clonal offspring ( $T$; Fig. 4). However, this was to a large extent $(67 \%)$ compensated by positive contributions to $\lambda$ by higher growth rates $(G)$ in good years and especially higher clonal reproduction $(C)$ throughout the study period (Fig. 4). The other two sites showed the reverse pattern of contributions. 


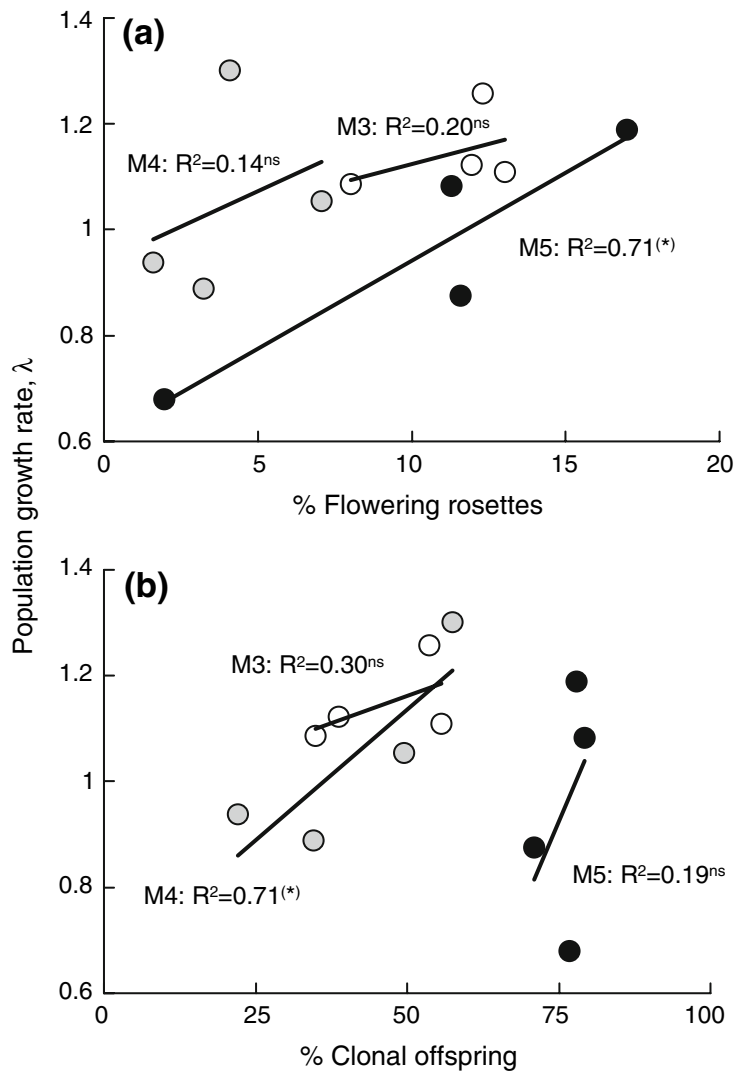

Fig. 3 Correlation between projected population growth rate, $\lambda$, and the proportion of all rosettes that are flowering $($ flow + cl.f $)$ or the proportion of all rosettes newly formed by clonal propagation $(c l . v+c l . f)$ in the stable stage distribution. Please note that the contribution of sexual reproduction to $\lambda$ is very small, but that flowering rosettes produce more clonal offspring than vegetative rosettes. Sites: Bennekomse meent (M3; open circles), Konijnendijk (M4; gray circles) and Veerslootlanden (M5; black circles). ns = not significant; $* P<0.10$

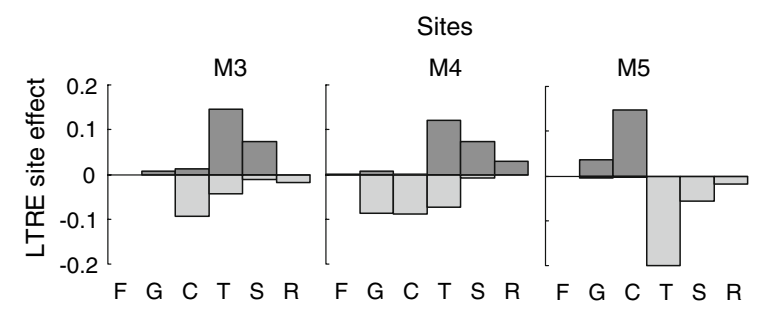

Fig. 4 Effects of three Cirsium dissectum populations in a $\lambda$ variance decomposition (LTRE). Positive and negative contributions of matrix elements are separately grouped by life history component: fecundity $(F)$, growth $(G)$, clonal reproduction $(C)$, survival of clonal offspring $(T)$, stasis $(S)$, and retrogression $(R)$. Mean $\lambda$ is $1.141,1.043$, and 0.968 , and net LTRE site effects, $\alpha$, is $+0.072,-0.025$, and -0.097 for sites M3, M4, and M5 respectively
The lower population growth rates in M5 (Fig. 2) resulted in a considerable number of extinctions in the simulations: $50 \%$ of the simulated populations that started with 100 rosettes went extinct within 78 years and $73 \%$ was extinct within 100 years. When the initial populations contained 10,000 rossettes, only $7.0 \%$ was extinct within 100 years and $50 \%$ within 159 years. None of the simulated M3 and M4 populations went extinct.

Garden experiment: effect of nutrient enrichment on clonal spread and rosette turn-over

The nutrient addition treatment increased the biomass of the tall grass M. caerulea, and increased the proportion of plots in which $C$. dissectum went extinct (from $10 \%$ to $43 \%$; see also Jongejans et al. 2006a). However, nutrient enrichment had no effect on the total biomass of $C$. dissectum in the plots with survivors: neither the number of living rosettes $(P=0.94$, Fig. 5a) nor the average dry weight of individual rosettes were affected ( $P=0.41$, Fig. 5b; see Appendix 2 for the details of the statistical analyses). Our new data show, however, that the flowering proportion of those rosettes was significantly higher in the plots that received nutrients $(P=0.0091$, Fig. $5 \mathrm{c})$. The rosettes in the nutrient-rich plots were also significantly further away from the position of the first, planted rosette $\left(P<2.2 \times 10^{-16}\right.$, Fig. 5d), and also further away from the hexagon of planted grasses. This increased clonal spread could not be explained by differential rhizome length, as this parameter did not differ between nutrient treatments $(P=0.87$, Fig. $5 e)$. The higher numbers of dead rosettes in the nutrientenriched plots $(P=0.045$, Fig. $5 f)$ suggest a higher turn-over rate. Since all plots started with one planted ramet, both rosette production and rosette mortality must have been higher in the nutrient-added plots. This increased mortality was due to both an increase in the proportion of rosettes that had flowered (19\% vs. $2 \%$ in the fertilized and control groups, respectively) and then automatically died, and due to an increase in the proportion of rosettes that were dead but had not flowered ( $29 \%$ vs. $15 \%$, respectively). On average $30 \%$ of the rosettes were still connected by intact rhizomes to at least one other rosette, which did not differ between the nutrient treatments. The other rhizomes had decayed over the 3 years of the study. 


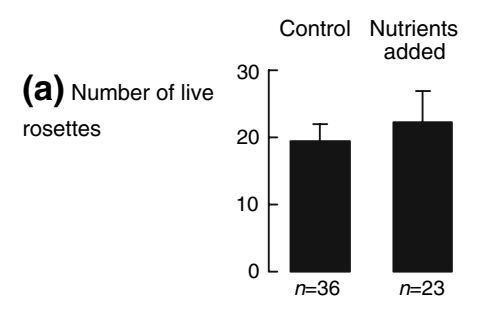

$$
\begin{aligned}
& \text { (b) Total dry } \\
& \text { weight [g] per } \\
& \text { rosette }
\end{aligned}
$$

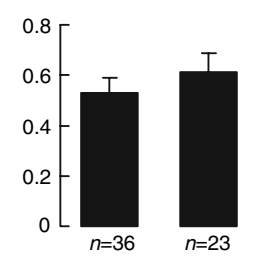

(c) Flowering percentage of live rosettes

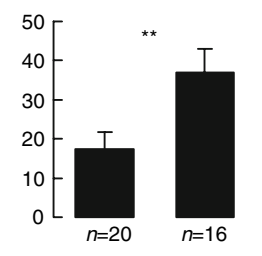

(d) Distance [cm] from the origin

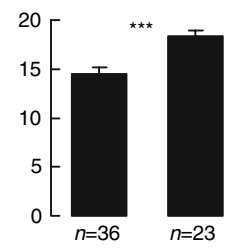

(e) Length $[\mathrm{cm}]$ of individual rhizomes

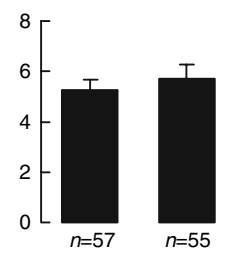

(f) Number of dead rosettes. grey=flowered black=vegetative

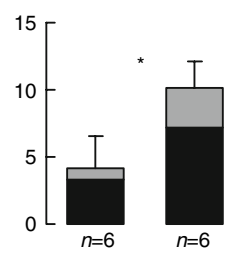

Fig. 5 Overview of the effect of nutrient addition on Cirsium dissectum in a garden experiment. The first four panels show results for the plots with survivors after 3 years: (a) number of rosettes alive (i.e., with green leaves) per plot at harvest, September 2002, (b) the total dry weight (g) of $C$. dissectum rosettes per plot at harvest, (c) the proportion of rosettes that flowered in June 2002 (of the plots without bud removal only), (d) the distance $(\mathrm{cm})$ of the rosettes at harvest measured from the position of the first, planted rosette at the beginning of the experiment. A total of 12 randomly selected plots were excavated to reveal the rhizomes: (e) the length $(\mathrm{cm})$ of all individual rhizomes that connected two rosettes, and (f) the number of dead rosettes per plot. See Appendix 2 for statistical details. $* P<0.05, * * P<0.01, * * * P<0.001$
Site survey: above- and below-ground plant performance in topsoil removed areas and in meadows along a productivity gradient

The grasslands ranged in mown biomass from 197 to $363 \mathrm{~g} \mathrm{~m}^{-2}$ and in mean vegetation height from 16 to $32 \mathrm{~cm}$ (Table 1). The areas in which the topsoil was removed had lower standing biomass (on average $81 \mathrm{~g} \mathrm{~m}^{-2}$ ), no humus layer and significantly more bare soil than grasslands. Cirsium dissectum rosette density varied greatly between plots which overruled differences between sites. The proportion of rosettes that flowered also varied strongly per plot and this proportion was largest in the most productive grassland and in one of the sod-cut areas. Seedlings were only found in the sod-cut areas (10 in total).

Average plant size, measured as the dry weight of the caudex, did not differ between grasslands, but tended to be lower in the sod-cut areas (Table 1). The caudex of flowering rosettes was heavier than the caudex of vegetative rosettes in both grasslands ( $t$-test after log-transformation: $F=6.1, \quad P=0.015$, $n=123)$ and sod-cut areas $(F=5.2, P=0.029$, $n=36)$. The number of rhizomes produced by an excavated rosette was positively correlated with its caudex weight $(r=0.46, \quad P<0.001)$. Flowering rosettes, which have heavier caudices, thus produced more rhizomes than vegetative rosettes: e.g. 0.32 vs. 2.0 for vegetative and flowering rosettes, respectively, in site M3, 0.29 vs. 1.0 in site M4, and 0.82 vs. 3.0 in site M5. Rhizome length (varying from close to the parent plant to up to $40 \mathrm{~cm}$ ) and depth did not differ systematically between sites, but in the sod-cut area of site TSR1 only short shallow rhizomes were found (Table 1). The rhizomes of C. dissectum almost always grew in a negative hyperbolic curve through the soil and seemed to be unhampered by soil types or by roots or tussocks of other species.

\section{Discussion}

Our garden experiment revealed that $C$. dissectum experiences higher extinction risks under more nutrient-rich conditions due to an inherent demographic vulnerability: although rosette formation and rosette growth increased due to increased nutrient availability, overall biomass did not increase because rosette survival decreased. By growing faster more 
rosettes reach the threshold size for flowering after which these monocarpic rosettes die. Field observations showed, however, that seedling establishment is nearly absent in the studied grasslands due to a lack of gaps in the vegetation. Increased flowering has little effect on population size and counting only flowering stems is therefore a less useful method for estimating population viability or extinction risks.

Our population model analyses showed a similar trend in survival, growth, flowering, and clonal propagation when comparing natural populations. The combination of studying demography in natural populations, with controlled experiments in which the effects of specific environmental changes (e.g., increased nutrient availability) or management options (e.g., topsoil removal) are studied, thus provides a mechanistic underpinning of the responses of individuals of an endangered species. Here this integrated approach leads to the conclusion that C. dissectum is vulnerable because it is a poor competitor that is unable to build up the plant biomass necessary to withstand competition with encroaching grasses.

\section{Clonal growth strategy of $C$. dissectum}

Instead of competing, $C$. dissectum escapes through clonal spread and this may result in finding vegetation gaps that allow rosette growth (Eriksson 1986; de Kroon and Schieving 1990). The increased clonal spread in the fertilized experimental garden plots was realized through the increased number of rosettes that were produced per plot. Rhizome length, however, was not responsive to experimental nutrient enrichment (which is consistent with the majority of studies reviewed by de Kroon and Hutchings 1995), nor did rhizome length differ between meadows. In the garden plots increased clonal spatial spread was a relatively efficient survival strategy, as the rhizomes broke through the hexagon of surrounding grasses and reached the circular edges of the plots which the more slowly expanding, dominant grasses had not colonized yet. Increased clonal spread in late-successional grasslands or in productive annuallymown meadows, however, is less useless if no gaps are created within a homogenous cover of competitive plants (Lenssen et al. 2005), and C. dissectum is likely to become extinct in such dense grasslands.
The population dynamics of only 3 populations were compared, and the sites not only differ in productivity, but also in other ways. For example, site M5 had more peaty soils than the other two. Nevertheless, the pattern of positively correlated plant growth and rosette turn-over was also found among field sites in which $C$. dissectum still occurred. The $\lambda$ variation decomposition (LTRE) confirmed that rosette growth and clonal propagation strongly determined the variation in population growth rate in the field and that their effects were buffered by the negatively correlated rosette survival. These trends in the field are consistent with the growth response to nutrient enrichment in the experiment.

In contrast to $C$. dissectum, co-occurring grassland perennials (Succisa pratensis Moench and Centaurea jacea L.) increased their competitiveness toward dominant grasses under the nutrient-enriched succession in the same garden experiment (Jongejans et al. 2006a). These perennials were able to build up more biomass in long-lived organs like rosette bases, leaves, and woody root systems, through which these species secure the positions they occupy within the vegetation for many years. Cirsium dissectum cannot increase its competitiveness because its rosettes stay small as we found in our garden experiment and in the comparison between grasslands. Furthermore, the single flowering stalks do not carry the few leaves high up in the vegetation canopy. The rosettes die after flowering and the clonal offspring generally have to establish away from the location that their parents occupied. Clonal plants with runners that successfully spread under later-successional vegetation stages [e.g., Brachypodium pinnatum (L.) Beauv. (de Kroon and Bobbink 1997) or Pteridium aquilinum (L.) Kuhn (Marrs and Watt 2006)] combine their clonality with biomass retention and with intact connections between ramets to continuously support new shoots, which $C$. dissectum does not.

Sexual reproduction in the clonal $C$. dissectum

Sexual reproduction is important for the regional survival and population dynamics of $C$. dissectum as the wind-dispersed seeds can potentially reach empty patches like recently sod-cut areas. The local population dynamics as quantified in our matrix population models, however, are almost entirely based on clonal 
propagation and rosette survival, since the establishment of seedlings is very rare. Kay and John (1994) found no seedlings at all in their survey of British populations. The 3 seedlings we found in our grasslands over 5 years made up only $0.1 \%$ of the observed rosettes per census, and they died before the next census. The low number of seedlings in $C$. dissectum is caused partly by poor seed production but primarily by very low establishment rates per seed within vegetation stands (Jongejans et al. 2006b). The presence of seedlings in the topsoil removed areas strongly suggests that seedling establishment in meadows is limited by competition. Acidification of the soil could have further reduced establishment probabilities in the meadows (Dorland et al. 2005). In Dutch meadows C. dissectum, therefore, seems to be an initial seedling recruitment (ISR) species, in which establishment of new genets only occurs in a short period in the early successional stages (for instance after sod-cutting). Genetic diversity can then be expected to decrease very slowly over time (Hartnett and Bazzaz 1985; de Kroon et al. 1992; Eriksson 1993, 1997).

Local adaptation to changing growing conditions as site productivity increases is thus unlikely in the grassland populations we investigated as almost all rosettes are produced clonally. In a common greenhouse environment, for instance, rhizome formation did not differ among $C$. dissectum rosettes collected in the same 5 meadows (Jongejans 2004). Distinct C. dissectum populations in The Netherlands have been shown to differ genetically (Smulders et al. 2000, using AFLPs) suggesting establishment and survival of multiple genotypes, but genetic variation between sites was smaller than within sites and may well be due to genetic drift. Disentangling the exact role of genetic variation on the variation in life history components within and between $C$. dissectum populations would require a more detailed genetic analysis.

\section{Implications}

Cirsium dissectum is restricted to a limited abiotic range due to its sensitivity to the effects of acidification (de Graaf et al. 1998; Lucassen et al. 2003). We add that $C$. dissectum is also vulnerable because its demographic responses make it a poor competitor. Our experiments showed that the role of rhizomes in this clonal species seems to be restricted to spreading new rosettes in order to explore heterogeneous environments, as the rhizomes are relatively shortlived and do not function as storage organs or as a means of resource sharing between rosettes after the initial phase. Our models revealed that clonal propagation is a major component of the population dynamics of $C$. dissectum. However, this explorative strategy is not successful in nutrient-enriched grasslands with homogeneous cover by more competitive species.

How should managers of nature reserves conserve this type of declining species? Genetic diversity could be increased by planting young rosettes grown from local seeds when seedling establishment no longer occurs in senile populations. Furthermore, our analyses highlight two aspects of the life history of C. dissectum that form suitable targets for management that does not involve the introduction of (local) plant material: the natural establishment and survival of both seedlings and clonal offspring. Sod-cutting patches in late-successional grasslands or periodically introducing trampling grazers therefore seem good options since small-scale disturbances facilitate the explorative strategy of clonal species like $C$. dissectum. Creating gaps in the vegetation also enables the otherwise strongly limited establishment of seedlings in the grasslands. Earlier reported negative effects of initial ammonium peaks after sod-cutting (Dorland et al. 2003) do not seem to limit seedling establishment in the long run, provided that seed sources are nearby. A positive aspect of nutrient-enrichment in these grasslands is that the elevated seed production may result in higher colonization rates of sod-cut areas, provided again that those new habitats are not too far away from the seed source.

Acknowledgments Ben Starink assisted with the site survey. Lidewij H. Keser made the drawings in Fig. 1. We are also grateful to Nienke Hartemink, Frans Möller, Henk van Roekel, Herman Klees, Jan van Walsem, Jasper van Ruijven, Juul Limpens, Louis de Nijs, Maurits Gleichman, and Pauline van Diepen for their practical assistance with the garden experiment, and to the Dutch State Forestry for their kind permission to perform this study in their meadows. The Netherlands Organization for Scientific Research funded this research (NWO project 805-33-452).

Open Access This article is distributed under the terms of the Creative Commons Attribution Noncommercial License which permits any noncommercial use, distribution, and reproduction in any medium, provided the original author(s) and source are credited. 


\section{Appendix1}

The transition matrix model used for the $C$. dissectum populations was:

\begin{tabular}{llllllll}
\hline & \multicolumn{9}{l}{ Year $\mathrm{t}$} & & & & \\
\cline { 3 - 8 } & & sdl & sml & lrg & flow & cl.v & cl.f \\
\hline Year $\mathrm{t}+1$ & sdl & $\mathrm{S}_{11}$ & 0 & 0 & $\mathrm{~F}_{14}$ & 0 & $\mathrm{~F}_{16}$ \\
& sml & $\mathrm{G}_{21}$ & $\mathrm{~S}_{22}$ & $\mathrm{R}_{23}$ & $\mathrm{~F}_{24}$ & $\mathrm{~T}_{25}$ & $\mathrm{~F}_{26}$ \\
& lrg & 0 & $\mathrm{G}_{32}$ & $\mathrm{~S}_{33}$ & 0 & $\mathrm{~T}_{35}$ & 0 \\
& flow & 0 & $\mathrm{G}_{42}$ & $\mathrm{G}_{43}$ & 0 & $\mathrm{~T}_{45}$ & 0 \\
& cl.v & 0 & $\mathrm{C}_{52}$ & $\mathrm{C}_{53}$ & $\mathrm{C}_{54}$ & $\mathrm{C}_{55}$ & $\mathrm{C}_{56}$ \\
& cl.f & 0 & $\mathrm{C}_{62}$ & $\mathrm{C}_{63}$ & $\mathrm{C}_{64}$ & $\mathrm{C}_{65}$ & $\mathrm{C}_{66}$ \\
\hline
\end{tabular}

The 6 stage classes of the matrix are: seedlings $(s d l)$, small $(\mathrm{sml})$ and large $(\mathrm{lrg})$ vegetative rosettes, flowering rosettes (flow), and new clonal offspring that either flower (cl.f) or not (cl.v). All flowering rosettes die. If non-flowering clonal offspring (cl.v) survive till the next year these rosettes become either $s m l, l r g$, or flow. The matrix elements are classified as either fecundity $(F)$, growth $(G)$, clonal reproduction $(C)$, survival of clonal offspring $(T)$, stasis $(S)$, and retrogression $(R)$. The elements of the 12 constructed matrices are given below. $\mathrm{S}_{11}=0.300, \mathrm{G}_{21}=0.150$ in all matrices.

\begin{tabular}{|c|c|c|c|c|c|c|c|c|c|c|c|c|}
\hline & \multicolumn{4}{|l|}{ M3 } & \multicolumn{4}{|l|}{ M4 } & \multicolumn{4}{|l|}{ M5 } \\
\hline & $\begin{array}{l}1999- \\
2000\end{array}$ & $\begin{array}{l}2000- \\
2001\end{array}$ & $\begin{array}{l}2001- \\
2002\end{array}$ & $\begin{array}{l}2002- \\
2003\end{array}$ & $\begin{array}{l}1999- \\
2000\end{array}$ & $\begin{array}{l}2000- \\
2001\end{array}$ & $\begin{array}{l}2001- \\
2002\end{array}$ & $\begin{array}{l}2002- \\
2003\end{array}$ & $\begin{array}{l}1999- \\
2000\end{array}$ & $\begin{array}{l}2000- \\
2001\end{array}$ & $\begin{array}{l}2001- \\
2002\end{array}$ & $\begin{array}{l}2002 \\
2003\end{array}$ \\
\hline $\mathrm{S}_{22}$ & 0.148 & 0.000 & 0.067 & 0.000 & 0.378 & 0.571 & 0.325 & 0.652 & 0.143 & 0.053 & 0.000 & 0.053 \\
\hline $\mathrm{G}_{32}$ & 0.593 & 0.333 & 0.433 & 0.455 & 0.076 & 0.036 & 0.229 & 0.101 & 0.714 & 0.579 & 0.571 & 0.579 \\
\hline $\mathrm{G}_{42}$ & 0.037 & 0.000 & 0.033 & 0.000 & 0.059 & 0.054 & 0.036 & 0.011 & 0.000 & 0.000 & 0.000 & 0.000 \\
\hline $\mathrm{C}_{52}$ & 0.222 & 0.333 & 0.400 & 0.273 & 0.437 & 0.679 & 0.265 & 0.202 & 0.714 & 0.526 & 0.429 & 0.526 \\
\hline $\mathrm{C}_{62}$ & 0.000 & 0.000 & 0.033 & 0.000 & 0.042 & 0.000 & 0.012 & 0.000 & 0.286 & 0.105 & 0.000 & 0.105 \\
\hline $\mathrm{R}_{23}$ & 0.034 & 0.208 & 0.047 & 0.024 & 0.256 & 0.350 & 0.143 & 0.361 & 0.019 & 0.150 & 0.083 & 0.032 \\
\hline $\mathrm{S}_{33}$ & 0.717 & 0.375 & 0.438 & 0.646 & 0.256 & 0.050 & 0.429 & 0.377 & 0.283 & 0.050 & 0.000 & 0.161 \\
\hline $\mathrm{G}_{43}$ & 0.069 & 0.067 & 0.156 & 0.146 & 0.070 & 0.150 & 0.000 & 0.033 & 0.415 & 0.100 & 0.000 & 0.065 \\
\hline $\mathrm{C}_{53}$ & 0.228 & 0.333 & 0.391 & 0.256 & 0.442 & 0.700 & 0.286 & 0.197 & 0.698 & 0.600 & 0.500 & 0.355 \\
\hline $\mathrm{C}_{63}$ & 0.007 & 0.042 & 0.016 & 0.012 & 0.047 & 0.000 & 0.000 & 0.000 & 0.226 & 0.050 & 0.000 & 0.032 \\
\hline $\mathrm{F}_{14}, \mathrm{~F}_{16}$ & 0.003 & 0.001 & 0.003 & 0.002 & 0.004 & 0.008 & 0.007 & 0.008 & 0.003 & 0.003 & 0.003 & 0.003 \\
\hline $\mathrm{F}_{24}, \mathrm{~F}_{26}$ & 0.006 & 0.003 & 0.005 & 0.004 & 0.008 & 0.016 & 0.015 & 0.016 & 0.005 & 0.006 & 0.006 & 0.006 \\
\hline $\mathrm{C}_{54}$ & 1.500 & 2.100 & 2.462 & 1.600 & 1.500 & 2.333 & 0.909 & 0.667 & 2.579 & 2.238 & 1.714 & 2.298 \\
\hline $\mathrm{C}_{64}$ & 0.000 & 0.300 & 0.154 & 0.100 & 0.150 & 0.000 & 0.000 & 0.000 & 0.842 & 0.190 & 0.000 & 0.426 \\
\hline $\mathrm{T}_{25}$ & 0.052 & 0.104 & 0.072 & 0.017 & 0.415 & 0.436 & 0.367 & 0.488 & 0.017 & 0.044 & 0.011 & 0.007 \\
\hline $\mathrm{T}_{35}$ & 0.530 & 0.333 & 0.494 & 0.633 & 0.161 & 0.040 & 0.235 & 0.163 & 0.175 & 0.121 & 0.151 & 0.244 \\
\hline $\mathrm{T}_{45}$ & 0.104 & 0.125 & 0.120 & 0.083 & 0.035 & 0.050 & 0.036 & 0.013 & 0.025 & 0.055 & 0.000 & 0.037 \\
\hline $\mathrm{C}_{55}$ & 0.315 & 0.333 & 0.386 & 0.258 & 0.375 & 0.683 & 0.271 & 0.200 & 0.467 & 0.604 & 0.480 & 0.356 \\
\hline $\mathrm{C}_{65}$ & 0.024 & 0.042 & 0.024 & 0.017 & 0.003 & 0.000 & 0.006 & 0.000 & 0.032 & 0.055 & 0.017 & 0.037 \\
\hline $\mathrm{C}_{56}$ & 2.063 & 2.063 & 2.500 & 1.571 & 2.000 & 2.400 & 2.000 & 2.000 & 1.960 & 2.207 & 1.750 & 1.960 \\
\hline $\mathrm{C}_{66}$ & 0.125 & 0.125 & 0.125 & 0.143 & 0.000 & 0.000 & 0.000 & 0.000 & 0.160 & 0.207 & 0.063 & 0.160 \\
\hline
\end{tabular}




\section{Appendix 2}

In this appendix we present the statistical analyses of the garden experiment. We used R (R Development Core Team 2007) to analyze the differences between the control and nutrient-enriched group as presented in Fig. 5. The experiment had a full-factorial design with 2 levels for each of 2 factors: Nutrient enrichment (control and enriched) and Bud removal (control and bud removal). The 6 parameters presented in Fig. 5 will be dealt with here in the same order, one at a time.

Number of live rosettes

A Generalized Linear Model (GLM) with quasipoisson error distribution was applied to these overdispersed (residual deviance was 886 on 55 degrees of freedom) count data. The coefficients of the model were:

\begin{tabular}{lllrl}
\hline Factor level & Estimate & $\begin{array}{l}\text { Std. } \\
\text { Error }\end{array}$ & $t$ value & $\operatorname{Pr}(>|\mathrm{t}|)$ \\
\hline (Intercept) & 2.824 & 0.220 & 12.855 & $<2 \times 10^{-16 * * *}$ \\
Nutrients & 0.027 & 0.371 & 0.072 & 0.943 \\
Bud removal & 0.286 & 0.298 & 0.958 & 0.342 \\
Nutrients:bud & 0.125 & 0.473 & 0.264 & 0.793 \\
$\quad$ Removal & & & & \\
\hline
\end{tabular}

Total dry weight $(\mathrm{g})$ per rosette

Since the data followed a normal distribution a twoway ANOVA was applied:

\begin{tabular}{|c|c|c|c|c|c|}
\hline Factor & Df & $\begin{array}{l}\text { Sum } \\
\mathrm{Sq}\end{array}$ & $\begin{array}{l}\text { Mean } \\
\text { Sq }\end{array}$ & $F$ value & $\operatorname{Pr}(>\mathrm{F})$ \\
\hline Nutrients & 1 & 0.088 & 0.088 & 0.701 & 0.406 \\
\hline Bud removal & 1 & 0.0011 & 0.0011 & 0.0087 & 0.926 \\
\hline $\begin{array}{l}\text { Nutrients:bud } \\
\text { removal }\end{array}$ & 1 & 0.001 & 0.0011 & 0.0087 & 0.926 \\
\hline Residuals & 54 & 6.774 & 0.125 & & \\
\hline
\end{tabular}

Flowering percentage of live rosettes

The number of live rosettes that flowered in each plot (compared to the number of live rosettes that did not flower) was analyzed with a GLM with a quasibinomial error distribution, since these binomial data were overdispersed (the residual deviance was 104 on 33 degrees of freedom). This time only plots without bud removal were analyzed because bud removal affected flowering directly. The coefficients of the model were:

\begin{tabular}{lrlrl}
\hline $\begin{array}{l}\text { Factor } \\
\text { level }\end{array}$ & Estimate & $\begin{array}{l}\text { Std. } \\
\text { Error }\end{array}$ & $t$ value & $\operatorname{Pr}(>|\mathrm{t}|)$ \\
\hline (intercept) & 1.099 & 0.216 & 5.077 & $1.47 \times 10^{-5} * * *$ \\
nutrients & -0.805 & 0.291 & -2.770 & $0.0091 * *$ \\
\hline
\end{tabular}

Distance $(\mathrm{cm})$ from the origin

The distances from each rosette to the position of the original rosette were normally distributed and analyzed with a two-way ANOVA with a nested error term to account for the fact that rosette distances were nested within plots:

\begin{tabular}{lrrrrr}
\hline Factor & Df & $\begin{array}{l}\text { Sum } \\
\text { Sq }\end{array}$ & $\begin{array}{l}\text { Mean } \\
\text { Sq }\end{array}$ & $\begin{array}{l}F \\
\text { value }\end{array}$ & $\operatorname{Pr}(>\mathrm{F})$ \\
\hline Nutrients & 1 & 1,881 & 1881 & 114 & $\begin{array}{c}<2.2 \times \\
10^{-16} * * * \\
\text { Bud } \\
\text { removal }\end{array}$ \\
$\begin{array}{c}\text { Nutrients: } \\
\text { bud } \\
\text { removal } \\
\text { Residuals }\end{array}$ & 1 & 195 & 195 & 11.8 & $0.00062 * * *$ \\
\hline
\end{tabular}

Length of individual rhizomes

The length of the excavated rhizomes were normally distributed data and analyzed with a two-way ANOVA with a nested error term to account for the fact that rhizome lengths were nested within the 12 analyzed plots: 


\begin{tabular}{lrrrrr}
\hline Factor & Df & Sum Sq & $\begin{array}{l}\text { Mean } \\
\text { Sq }\end{array}$ & $F$ value & $\operatorname{Pr}(>\mathrm{F})$ \\
\hline Nutrients & 1 & 0.35 & 0.35 & 0.027 & 0.869 \\
Bud removal & 1 & 2.21 & 2.21 & 0.171 & 0.681 \\
$\begin{array}{l}\text { Nutrients:bud } \\
\text { removal }\end{array}$ & 1 & 3.92 & 3.92 & 0.302 & 0.584 \\
$\begin{array}{c}\text { Residuals } \\
\text { Ren }\end{array}$ & 107 & 1,389 & 13.0 & & \\
\hline
\end{tabular}

Number of dead rosettes

A GLM was applied to the number of dead rosettes in the 12 excavated plots. The count data was overdispersed (residual deviance was 33 on 8 degrees of freedom) and therefore a quasipoisson error distribution was used. The coefficients of the model were:

\begin{tabular}{rllll}
\hline Factor level & Estimate & $\begin{array}{l}\text { Std. } \\
\text { Error }\end{array}$ & value & $\operatorname{Pr}(>|\mathrm{t}|)$ \\
\hline (Intercept) & $9.31 \times 10^{-7}$ & 1.03 & $9.02 \times 10^{-7}$ & 1.000 \\
Nutrients & 2.54 & 1.07 & 2.37 & $0.045 *$ \\
Bud Removal & 1.99 & 1.10 & 1.81 & 0.108 \\
$\begin{array}{l}\text { Nutrients:bud } \\
\text { removal }\end{array}$ & -2.50 & 1.20 & -2.08 & 0.071 \\
\hline
\end{tabular}

\section{References}

Abrahamson WG (1980) Demography and vegetative reproduction. In: Solbrig OT (ed) Demography and evolution in plant populations. Blackwell, Oxford

Berg H (2002) Population dynamics in Oxalis acetosella: the significance of sexual reproduction in a clonal, cleistogamous forest herb. Ecography 25(2):233-243

Blackstock TH, Stevens DP, Stevens PA, Mockridge CP, Yeo MJM (1998) Edaphic relationships among Cirsio-Molinietum and related wet grassland communities in lowland Wales. J Veg Sci 9(3):431-444

Boyce MS (1992) Population viability analysis. Annu Rev Ecol Syst 23:481-506

Buck-Sorlin G (1993) Ausbreitung und Rückgang der Englischen Kratzdistel-Cirsium dissectum (L.) Hill-in Nordwestdeutschland. Tuexenia 13:183-191

Buck-Sorlin G, Weeda EJ (2000) Oecologie en plantensociologische positie van Cirsium dissectum (L.) Hill in Oostfriesland. Stratiotes 21:3-12
Caswell H (2001) Matrix population models. Construction, analysis, and interpretation. Sinauer, Sunderland

Caswell H, Werner PA (1978) Transient behavior and life history analysis of teasel (Dipsacus sylvestris Huds). Ecology 59(1):53-66

Cochran ME, Ellner S (1992) Simple methods for calculating age-based life history parameters for stage-structured populations. Ecol Monogr 62(3):345-364

Colling G, Matthies D (2006) Effects of habitat deterioration on population dynamics and extinction risk of an endangered, long-lived perennial herb (Scorzonera humilis). J Ecol 94(5):959-972. doi:10.1111/j.1365-2745.2006.01147.x

de Graaf MCC, Bobbink R, Verbeek PJM, Roelofs JGM (1997) Aluminium toxicity and tolerance in three heathland species. Water Air Soil Pollut 98(3-4):229-239

de Graaf MCC, Bobbink R, Roelofs JGM, Verbeek PJM (1998) Differential effects of ammonium and nitrate on three heathland species. Plant Ecol 135(2):185-196. doi:10.1023/A:1009717613380

de Kroon H, Bobbink R (1997) Clonal plant dominance under elevated nitrogen deposition, with special reference to Brachypodium pinnatum in chalk grassland. In: de Kroon $\mathrm{H}$, van Groenendael J (eds) The ecology and evolution of clonal plants. Backhuys, Leiden

de Kroon H, Hutchings MJ (1995) Morphological plasticity in clonal plants: the foraging concept reconsidered. J Ecol 83(1):143-152

de Kroon H, Schieving F (1990) Resource partitioning in relation to clonal growth strategy. In: van Groenendael J, de Kroon $\mathrm{H}$ (eds) Clonal growth in plants: regulation and function. SPB, The Hague

de Kroon H, Hara T, Kwant R (1992) Size hierarchies of shoots and clones in clonal herb monocultures: do clonal and nonclonal plants compete differently? Oikos 63(3): 410-419

de Vere N (2007) Biological flora of the British Isles: Cirsium dissectum (L.) Hill (Cirsium tuberosum (L.) All. subsp. anglicum (Lam.) Bonnier; Cnicus pratensis (Huds.) Willd., non Lam.; Cirsium anglicum (Lam.) DC.). J Ecol 95(4):876-894. doi:10.1111/j.1365-2745.2007.01265.x

Dorland E, Bobbink R, Messelink JH, Verhoeven JTA (2003) Soil ammonium accumulation after sod cutting hampers the restoration of degraded wet heathlands. J Appl Ecol 40(5):804-814. doi:10.1046/j.1365-2664.2003.00845.x

Dorland E, Hart MAC, Vermeer ML, Bobbink R (2005) Assessing the success of wet heath restoration by combined sod cutting and liming. Appl Veg Sci 8:209-218

Efron B (1982) The jackknife, the bootstrap and other resampling plans. Society for industrial and applied mathematics, Philadelphia

Ehrlén J (2003) Fitness components versus total demographic effects: evaluating herbivore impacts on a perennial herb. Am Nat 162(6):796-810. doi:10.1086/379350

Ehrlén J, Syrjänen K, Leimu R, Garcia MB, Lehtilä K (2005) Land use and population growth of Primula veris: an experimental demographic approach. J Appl Ecol 42(2):317-326. doi:10.1111/j.1365-2664.2005.01015.x

Eriksson O (1986) Mobility and space capture in the stoloniferous plant Potentilla anserina. Oikos 46(1):82-87

Eriksson O (1993) Dynamics of genets in clonal plants. Trends Ecol Evol 8(9):313-316. doi:10.1016/0169-5347(93)90237-J 
Eriksson O (1997) Clonal life histories and the evolution of seed recruitment. In: de Kroon H, van Groenendael JM (eds) The ecology and evolution of clonal plants. Backhuys, Leiden

Gotelli NJ, Ellison AM (2002) Nitrogen deposition and extinction risk in the northern pitcher plant, Sarracenia purpurea. Ecology 83(10):2758-2765. doi:10.1890/0012-9658(2002) 083[2758:NDAERI]2.0.CO;2

Griffith AB, Forseth IN (2005) Population matrix models of Aeschynomene virginica, a rare annual plant: implications for conservation. Ecol Appl 15(1):222-233. doi:10.1890/ 02-5219

Hartnett DC, Bazzaz FA (1985) The genet and ramet population dynamics of Solidago canadensis in an abandoned field. J Ecol 73(2):407-413

Horvitz C, Schemske DW, Caswell H (1997) The relative "importance" of life-history stages to population growth: prospective and retrospective analyses. In: Tuljapurkar S, Caswell $\mathrm{H}$ (eds) Structured-population models in marine, terrestrial, and freshwater systems. Chapman \& Hall, New York

Jongejans E. 2004. Life history strategies and biomass allocation. The population dynamics of perennial plants in a regional perspective. Dissertation, Wageningen University

Jongejans E, de Kroon H (2005) Space versus time variation in the population dynamics of three co-occurring perennial herbs. J Ecol 93(4):681-692. doi:10.1111/j.1365-2745. 2005.01003. $\mathrm{x}$

Jongejans E, de Kroon H, Berendse F (2006a) The interplay between shifts in biomass allocation and costs of reproduction in four grassland perennials under simulated successional change. Oecologia 147(2):369-378. doi: 10.1007/s00442-005-0325-8

Jongejans E, Soons MB, de Kroon H (2006b) Bottlenecks and spatiotemporal variation in the sexual reproduction pathway of perennial meadow plants. Basic Appl Ecol 7(1):71-81. doi:10.1016/j.baae.2005.04.004

Kalisz S, McPeek MA (1992) Demography of an age-structured annual-resampled projection matrices, elasticity analyses, and seed bank effects. Ecology 73(3):1082-1093

Kay QON, John R (1994) Population genetics and demographic ecology of some scarce and declining vascular plants of Welsh lowland grassland and related habitats. Countryside Council for Wales Science Report No. 93, Bangor

Klimeš L, Klimesová J (2000) Plant rarity and the type of clonal growth. Z Ökol Naturschutz 9:43-52
Lenssen JPM, Shock C, Speek T, During HJ, de Kroon H (2005) Experimental ramet aggregation in the clonal plant Agrostis stolonifera reduces its competitive ability. Ecology 86(5):1358-1365. doi:10.1890/04-0939

Loehle C (1987) Partitioning of reproductive effort in clonal plants: a benefit-cost model. Oikos 49(2):199-208

Lucassen ECHET, Bobbink R, Smolders AJP, van der Ven PJM, Lamers LPM, Roelofs JGM (2003) Interactive effects of low $\mathrm{pH}$ and high ammonium levels responsible for the decline of Cirsium dissectum (L.) Hill. Plant Ecol 165(1):45-52. doi:10.1023/A:1021467320647

Marrs RH, Watt AS (2006) Biological flora of the British Isles: Pteridium aquilinum (L.) Kuhn. J Ecol 94(6):1272-1321. doi:10.1111/j.1365-2745.2006.01177.x

Maschinski J, Baggs JE, Quintana-Ascencio PE, Menges ES (2006) Using population viability analysis to predict the effects of climate change on the extinction risk of an endangered limestone endemic shrub, Arizona cliffrose. Conserv Biol 20(1):218-228. doi:10.1111/j.1523-1739.2006.00272.x

Menges ES (1990) Population viability analysis for an endangered plant. Conserv Biol 4(1):52-62

Menges ES (2000) Population viability analysis in plants: challenges and opportunities. Trends Ecol Evol 15(2):5156. doi:10.1016/S0169-5347(99)01763-2

R Development Core Team (2007) R: A language and environment for statistical computing. R Foundation for Statistical Computing, Vienna

Roem WJ, Berendse F (2000) Soil acidity and nutrient supply ratio as possible factors determining changes in plant species diversity in grassland and heathland communities. Biol Conserv 92(2):151-161. doi:10.1016/S0006-3207(99)00049-X

Saunders DA, Hobbs RJ, Margules CR (1991) Biological consequences of ecosystem fragmentation: a review. Conserv Biol 5(1):18-32

Smulders MJM, van der Schoot J, Geerts RHEM, Antonisse-De Jong AG, Korevaar H, van der Werf A, Vosman B (2000) Genetic diversity and the reintroduction of meadow species. Plant Biol 2(4):447-454. doi:10.1055/s-2000-6780

Soons MB, Messelink JH, Jongejans E, Heil GW (2005) Habitat fragmentation reduces grassland connectivity for both shortdistance and long-distance wind-dispersed forbs. J Ecol 93(6):1214-1225. doi:10.1111/j.1365-2745.2005.01064.x

Thompson K, Bakker JP, Bekker RM (1997) The soil seed banks of North West Europe: methodology, density and longevity. Cambridge University Press, Cambridge

van der Meijden R (1996) Heukels' flora van Nederland. Wolters-Noordhoff, Groningen, The Netherlands 